\title{
The influence of colored zirconia on the optical properties of all-ceramic restorations
}

\author{
Rino HARADA ${ }^{1}$, Shinji TAKEMOTO ${ }^{1,2}$, Masayuki HATTORI ${ }^{1, *}$, Masao YOSHINARI ${ }^{1,2}$, Yutaka ODA ${ }^{1}$ and Eiji KAWADA ${ }^{1}$ \\ ${ }^{1}$ Department of Dental Materials Science, Tokyo Dental College, 2-9-18 Misaki-cho, Chiyoda-ku, Tokyo 101-0061, Japan \\ ${ }^{2}$ Oral Health Center, Tokyo Dental College, 2-9-18 Misaki-cho, Chiyoda-ku, Tokyo 101-0061, Japan \\ *New affiliation from May 1st 2014: Department of Medical Engineering, Iwate Medical University, 2-1-1 Nishitokuta, Yahaba-cho, Shiwa-gun, Iwate \\ 028-3694, Japan \\ Corresponding author, Shinji TAKEMOTO; E-mail: takemoto@tdc.ac.jp
}

\begin{abstract}
This study investigated the effects of different colored tetragonal zirconia polycrystal (TZP) core on the optical properties of TZP framework restorations. Three various colors of TZP discs (Katana Zirconia) $14 \mathrm{~mm}$ in diameter and $0.5 \mathrm{~mm}$ thickness were layered with 2 shades of veneering ceramics (shade A1 and A4: Cerabian ZR). These specimens were polished to approximately $1.5 \mathrm{~mm}$. CIE $L^{*} a^{*} b^{*}$ coordinates, translucency (TP), and opalescence (OP) on the TZP restorations were evaluated. Consequently, TZP core color affected CIE $L^{*} a^{*} b^{*}$ values of TZP restorations however TP and OP did not significantly differ among the 3 core colors. Translucency and opalescence for colored TZP framework restorations were not influenced by the underlying TZP core color when veneering ceramics were layered to thicknesses of $1.0 \pm 0.1 \mathrm{~mm}$.
\end{abstract}

Keywords: Colored zirconia, Y-TZP, All-ceramic restorations, Translucency, Opalescence

\section{INTRODUCTION}

The complicated optical qualities of natural teeth make it extremely difficult to reproduce its color for crown restorations. For years, porcelain-fused-tometal restorations (PFM) were considered the "gold standard" due to their clinical performance and have been predominantly used as an esthetic option to restore teeth ${ }^{1,2)}$. However, the use of a metal coping introduces significant esthetic limitations due to the lack of translucency of the final restoration which dental tissues display to a high degree ${ }^{3}$. To overcome this issue, all ceramic restorations (ACR) were introduced as a metal-free alternative for conventional dental materials. ACR have shown to not only eliminate complications such as metal allergies or metallic collars, but also provide a durable restoration displaying exceptional biocompatibility, chemical inertness, esthetic qualities, and low plaque retention ${ }^{4-6)}$.

The recent use of zirconia as core material in ACR, is being highly evaluated based on its high flexural strength and fracture resistance ${ }^{7,8)}$. Tetragonal zirconia polycrystal (TZP) with 3 mol\% yttrium oxide $\left(\mathrm{Y}_{2} \mathrm{O}_{3}\right)$ is used widely in the field of dentistry today. Its luminous stark white color and opaque nature comes from its density, elemental chemistry and high crystallinity which results in a relatively high refractive index ${ }^{9,10}$. The addition of veneering ceramic on TZP cores to improve esthetics diminishes their advantage over ACR made of only feldspathic porcelain in terms of tooth reduction $^{11)}$. Its opaque nature and masking ability have demonstrated that TZP restorations require less tooth reduction than traditional feldspathic porcelain to sufficiently mask undesirable tooth colors ${ }^{11-133}$.

The optical properties of ceramic restorations could be influenced by thickness, surface texture, brands, batches, and number of firings of the porcelain, in addition to properties of the luting agent and abutment ${ }^{9,11-21)}$. Light transmittance and reflectance have important roles in the aesthetics of restorations and translucency is a property that is dependent on light scattering and absorbing characteristics as it contributes to the lifelike and natural appearance to ceramic restorations ${ }^{22,23)}$. Opalescence is a property where the material appears yellowish-red in transmitted light and blue in scattered light perpendicular to the transmitted light ${ }^{24)}$. Translucency and opalescence are properties that natural teeth possess thus they are essential factors for controlling esthetics when reproducing a natural dentition.

Recent advances have led to the introduction of colored TZP developed through staining or infiltrating chloride solution of rare earth elements at the presintered stage $^{10,25)}$. However, the above mentioned studies on the optical properties of ceramics leads to the question of whether or not the use of different TZP core colors would cause perceptible color differences on the final TZP restoration after veneering ceramics compared to when non-colored TZP are used. There have been few or some reports on the masking ability of TZP and the correlation between the thickness ratio of ceramic core and veneer on the final restoration color ${ }^{13,26-28)}$, however not much information has been published on optical aspects of ACR using colored TZP.

This study will go on to investigate the effects of colored TZP on the optical properties of TZP framework restorations after veneering ceramics. The optical properties evaluated were $\operatorname{CIE} L^{*} a^{*} b^{*}$ values, translucency and opalescence parameters. The null hypothesis is that the color of the TZP core has no effect 
on the final optical properties of the final restoration after veneering ceramics so long as the minimally suggested thickness of $1 \mathrm{~mm}$ is met.

\section{MATERIALS AND METHODS}

\section{Sample preparation}

TZP discs, $14 \mathrm{~mm}$ in diameter, were fabricated from 3 variations of colored TZP blocks KT10 ( $n=20)$, KT12 $(n=10), \quad \mathrm{KT} 14 \quad(n=10) \quad$ Katana Zirconia, Kuraray Noritake, Tokyo, Japan). Thickness of TZP discs were $0.54 \pm 0.02 \mathrm{~mm}$ after sintering. Sintering was performed at the Noritake Dental facility. The veneering surface was sandblasted with $50 \mu \mathrm{m}$ alumina for $5 \mathrm{~s}$ under 0.25 $\mathrm{MPa}$ with the nozzle placed $10 \mathrm{~mm}$ from the center of the specimen at $90^{\circ}$ incidence angle (Jalenko Jetblast Dental Lab Sandblaster, US). The discs were cleaned ultrasonically in acetone for $5 \mathrm{~min}$ to avoid surface contamination which can interfere with proper bonding of ceramic to the TZP.

Veneering ceramics, opacious body and body (Cerabien ZR, Kuraray Noritake Dental), shade A1 and A4 were fired on each color of TZP discs using a metal die $1.5 \mathrm{~mm}$ thick with a $8 \mathrm{~mm}$ hole for ceramic layering. Veneering ceramic was layered more than the necessary thickness in order to compensate for firing shrinkage (ca. 18\%) and final polishing procedures (ca. $50 \mu \mathrm{m})$. Five specimens of each combination were fabricated. First a thin layer of opacious body powder of each corresponding shade was mixed with a binding agent (Meister liquid, Kuraray Noritake Dental) then layered to a thickness of $0.4 \mathrm{~mm}$ and fired on a TZP disc and adjusted to approximately $0.3 \mathrm{~mm}$ by polishing. The layered opacious body was dried for $7 \mathrm{~min}$, decompressed (at $80 \mathrm{hPa}$ ) from 600 to $940^{\circ} \mathrm{C}$ at a rate of $45^{\circ} \mathrm{C}$ per min, held for $1 \mathrm{~min}$, released decompression, then cooled down for $4 \mathrm{~min}$. Body veneering ceramic was then layered to a thickness of approximately $0.9 \mathrm{~mm}$. The firing instruction was similar to that for the opacious body. Approximately 1.1 to $1.3 \mathrm{~mm}$ of veneering ceramic was layered and the final thickness was adjusted to $1.5 \pm 0.1 \mathrm{~mm}$ with the TZP core by polishing with a series of silicon carbide papers and finally buffed with $0.3 \mu \mathrm{m}$ alumina. The final thickness was adjusted to $1.5 \mathrm{~mm}$ with the core after fine polishing.

For KT10, samples with a layer of shade base ceramic (Cerabien ZR, Kuraray Noritake Dental) under the opacious body were fabricated to study its effect on final color: these are labelled as KT10 SB. The firing instructions for shade base was dry for $5 \mathrm{~min}$, decompression (at $80 \mathrm{hPa}$ ) from 600 to $930^{\circ} \mathrm{C}$ at a rate of $45^{\circ} \mathrm{C} / \mathrm{min}$, hold for $1 \mathrm{~min}$, release decompression, then cool down for $4 \mathrm{~min}$. Veneering ceramic samples at 1 mm thickness without the TZP core of each shade were fabricated to use as reference.

\section{Color analysis}

Color analysis was performed before and after firing with a colorimeter (VSS-300H, Nippon Denshoku Industries, Tokyo, Japan). The reflectance spectra of white and black backings were determined to calculate the Commission Internationale de l'Eclairage (CIE) $L^{*} a^{*} b^{*}$ color coordinates for CIE illuminant D65 and $0.5 \mathrm{~mm}$ slit size. The colorimeter was calibrated with a white calibration tile before being used. Table 1 shows the values for white and black background after calibration.

The optical properties of the veneered ceramics were measured, and transparency parameter (TP) and opalescence parameter (OP) were evaluated. To evaluate TP, CIE $L^{*} a^{*} b^{*}$ values from catoptric light on black (B) and white (W) background were determined and calculated with the following equation ${ }^{29)}$ :

$$
\mathrm{TP}=\left[\left(L_{\mathrm{B}}{ }^{*}-L_{\mathrm{W}}{ }^{*}\right)^{2}+\left(a_{\mathrm{B}}{ }^{*}-a_{\mathrm{W}}{ }^{*}\right)^{2}+\left(b_{\mathrm{B}}{ }^{*}-b_{\mathrm{W}}{ }^{*}\right)^{2}\right]^{1 / 2}
$$

To evaluate OP, CIE $L^{*} a^{*} b^{*}$ values from transmitted light $(\mathrm{T})$ and catoptric light $(\mathrm{R})$ were determined and calculated with the following equation ${ }^{29)}$ :

$$
\mathrm{OP}=\left[\left(a_{\mathrm{T}}{ }^{*}-a_{\mathrm{R}}{ }^{*}\right)^{2}+\left(b_{\mathrm{T}}{ }^{*}-b_{\mathrm{R}}{ }^{*}\right)^{2}\right]^{1 / 2}
$$

Color analysis was also performed with TZP core and fabricated ceramics independently to use as reference.

\section{Statistical analysis}

Statistical analysis of optical properties was performed with two-way ANOVA and Tukey's HSD multiple comparison tests among the different combinations

\begin{tabular}{|c|c|c|c|c|c|c|c|c|c|c|}
\hline \multirow{2}{*}{ Materials } & \multirow{2}{*}{ Code } & \multirow{2}{*}{$\begin{array}{l}\text { Thickness } \\
\text { (mm) }\end{array}$} & \multicolumn{3}{|c|}{ White background } & \multicolumn{3}{|c|}{ Black background } & \multirow{2}{*}{$\mathrm{TP}$} & \multirow{2}{*}{$\mathrm{OP}$} \\
\hline & & & $L^{*}$ & $a^{*}$ & $b^{*}$ & $L^{*}$ & $a^{*}$ & $b^{*}$ & & \\
\hline \multirow{3}{*}{ Zirconia core } & KT10 & $0.55 \pm 0.02$ & $84.4 \pm 0.3$ & $-0.1 \pm 0.1$ & $-0.9 \pm 0.2$ & $75.5 \pm 0.4$ & $0.3 \pm 0.2$ & $-3.9 \pm 0.2$ & $9.0 \pm 1.5$ & $13.8 \pm 4.4$ \\
\hline & KT12 & $0.54 \pm 0.01$ & $77.4 \pm 0.6$ & $-1.5 \pm 0.2$ & $7.2 \pm 0.4$ & $69.3 \pm 0.6$ & $-1.4 \pm 0.1$ & $1.4 \pm 0.2$ & $9.6 \pm 1.0$ & $8.0 \pm 1.8$ \\
\hline & KT14 & $0.52 \pm 0.03$ & $69.8 \pm 0.7$ & $0.1 \pm 0.3$ & $19.9 \pm 0.4$ & $67.3 \pm 1.8$ & $-2.3 \pm 0.4$ & $13.0 \pm 1.0$ & $7.0 \pm 0.5$ & $7.4 \pm 1.6$ \\
\hline \multirow{2}{*}{$\begin{array}{l}\text { Veneering } \\
\text { ceramics }\end{array}$} & A1 & $1.03 \pm 0.07$ & $70.8 \pm 1.0$ & $-1.9 \pm 0.3$ & $8.4 \pm 0.5$ & $61.8 \pm 0.5$ & $-1.9 \pm 0.3$ & $4.7 \pm 0.7$ & $9.7 \pm 1.7$ & $1.5 \pm 0.5$ \\
\hline & $\mathrm{A} 4$ & $1.04 \pm 0.07$ & $60.5 \pm 1.9$ & $0.9 \pm 0.3$ & $22.4 \pm 0.4$ & $54.5 \pm 1.1$ & $-0.9 \pm 0.5$ & $17.4 \pm 1.2$ & $8.0 \pm 3.1$ & $15.5 \pm 1.9$ \\
\hline \multirow{2}{*}{ Background } & White & - & 99.9 & 0.2 & -0.6 & - & - & - & - & - \\
\hline & Black & - & - & - & - & 5.8 & 2.5 & 2.9 & - & - \\
\hline
\end{tabular}

Table 1 Optical properties of materials used 

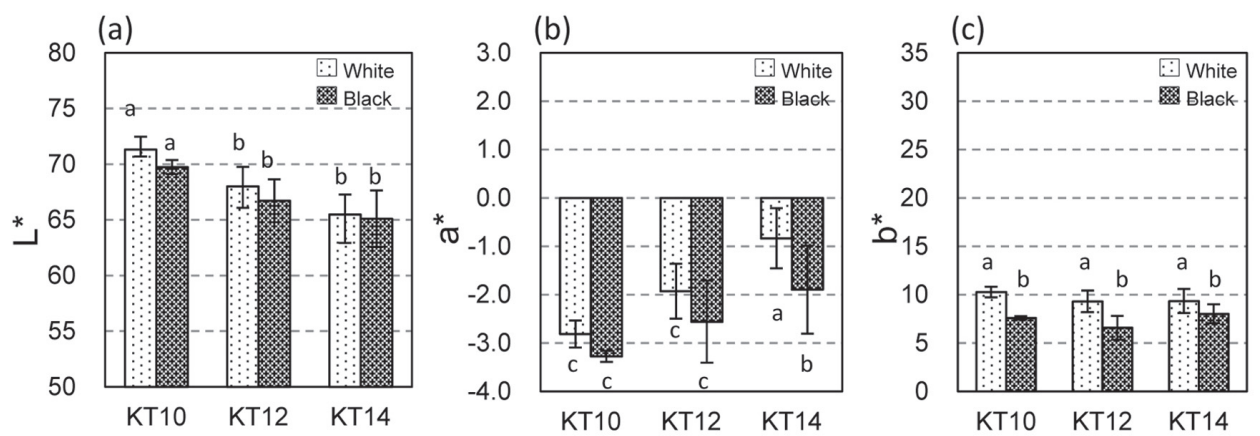

Fig. 1 Color coordinates $L^{*}(\mathrm{a}), a^{*}(\mathrm{~b}), b^{*}(\mathrm{c})$ on white and black backgrounds for veneering ceramics shade A1.

Same lower-case letters indicate no statistical differences among the samples $(p>0.05)$.
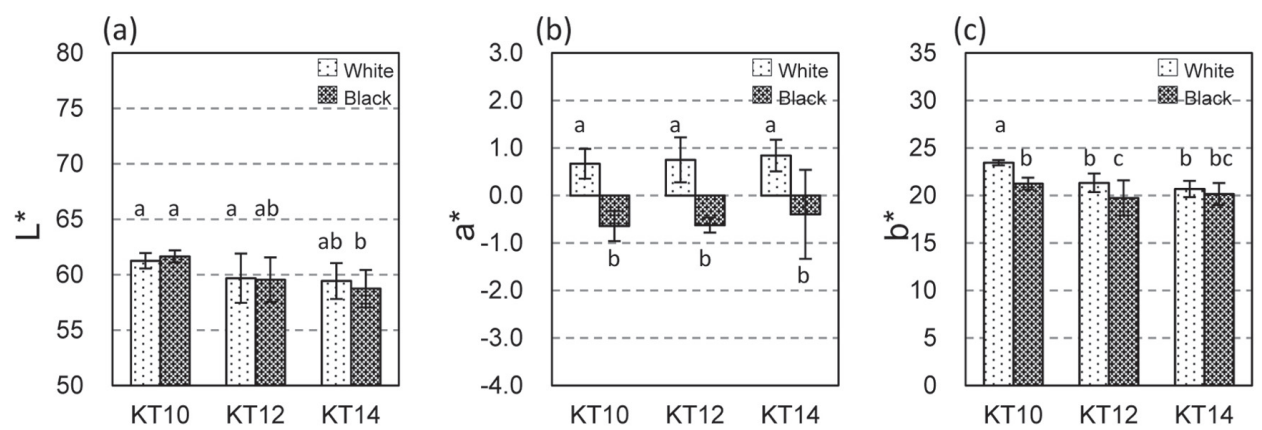

Fig. 2 Color coordinates $L^{*}(\mathrm{a}), a^{*}(\mathrm{~b}), b^{*}(\mathrm{c})$ on white and black backgrounds for veneering ceramics shade A4.

Same lower-case letters indicate no statistical differences among the samples $(p>0.05)$.

of TZP core and shade of veneering ceramics against black and white backgrounds in order to establish any relationships between background color, core materials, and veneering ceramics. In addition, differences in optical properties of veneering ceramics with and without shade base porcelain on TZP core (color KT10) was statistically performed using the $t$-test. Statistical software (Ekuseru-Toukei 2012, Social Survey Research Information, Tokyo, Japan) was used to perform analyses and all statistical significance was set at $\alpha=0.05$.

\section{RESULTS}

Table 1 lists the color coordinates (CIE $L^{*} a^{*} b^{*}$ ) against white and black background, translucency (TP), and opalescence (OP) for TZP core materials and veneering ceramics without core material. The colored TZP core caused a decrease in $L^{*}$ and an increase in $b^{*}$ in the order of KT10, KT12, and KT14, indicating that the color of TZP core materials has an influence on color coordinates of the final restoration. The TP values among TZP cores and veneering ceramics ranged from 7.0 to 9.7. The OP value for veneering ceramic shade A1 was 1.5, which was the smallest value among tested materials.

Figure 1 displays color coordinates $L^{*}(\mathrm{a}), a^{*}(\mathrm{~b})$, and $b^{*}(\mathrm{c})$ against white and black background for veneering ceramics shade A1 with TZP core. The $L^{*}$ values for KT 10, KT12, and KT14 were $71.3 \pm 1.1,67.9 \pm 1.6$, and $66.2 \pm 1.8$ against white background, and $69.7 \pm 0.6$, $65.9 \pm 2.1$, and $66.0 \pm 2.4$ against black background respectively. KT10 was significantly greater than KT12 and KT14 $(p<0.05)$, and no significant differences were observed between the white and black backgrounds $(p>0.05)$. This indicates that the brightness of veneering ceramics decrease as the core color becomes darker from $\mathrm{KT} 10$ to KT14.The $a^{*}$ values increased in the order of KT10, KT12, and KT14, and significant differences were observed for KT14 from the other colors and between the backgrounds $(p<0.05)$. The $b^{*}$ values for KT10, KT12, and KT14 were $10.3 \pm 0.5,9.3 \pm 0.2$, and $9.9 \pm 0.3$ against white background, and $7.6 \pm 0.2,6.4 \pm 1.4$, and $8.4 \pm 1.1$ against black background. No significant differences were observed between core colors $(p>0.05)$ but differences were observed between the white and black backgrounds $(p<0.05)$. For veneering ceramic color A1, darker core caused significant differences in $a^{*}(p<0.05)$ 

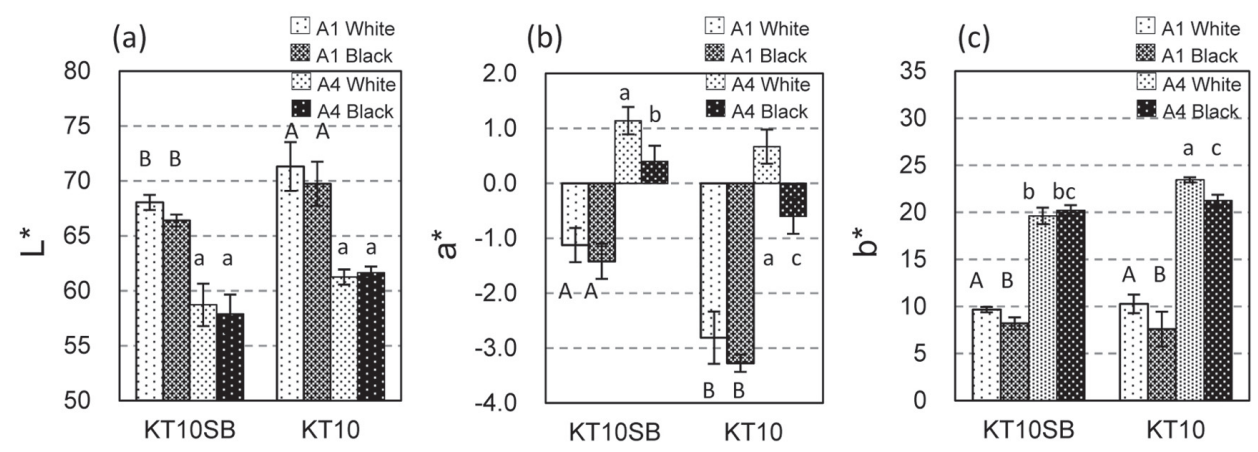

Fig. 3 Color coordinates $L^{*}(\mathrm{a}), a^{*}(\mathrm{~b}), b^{*}(\mathrm{c})$ on white and black backgrounds for veneering ceramics shade A1 and A4 on KT10 with shade base (KT10SB) and without shade base (KT10).

Same upper and lower-case letters indicate no statistical differences among the samples $(p>0.05)$.

(a)

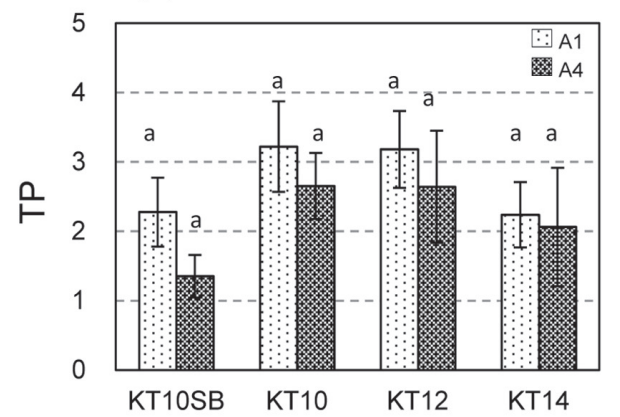

(b)

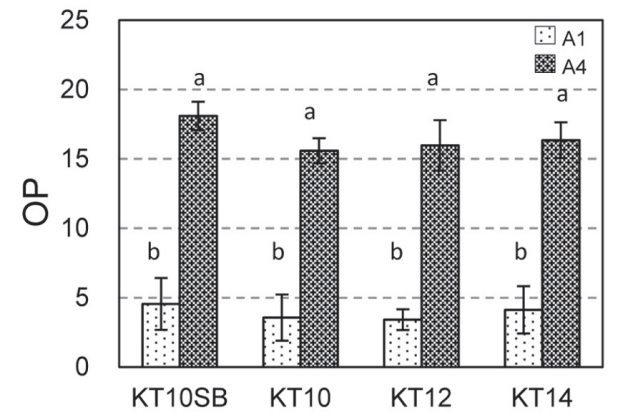

Fig. 4 Optical properties, TP and OP, for veneering ceramics shade A1 and A4 on colored zirconia cores.

Same lower-case letters indicate no statistical differences among the samples $(p>0.05)$.

however no effect on $b^{*}(p>0.05)$.

In comparison, the color coordinates for veneering ceramics shade A4 against white and black background are shown in Fig. 2. The $L^{*}$ values decreased with darker core regardless of background color $(p<0.05)$. No significant differences were seen among core colors for $a^{*}$ values $(p>0.05)$, however differences were observed between black and white background for all cores $(p<0.05)$. The $b^{*}$ values indicated that values decrease as core becomes darker. This indicates that core color influences brightness and chromaticity $\left(b^{*}\right)$ of the final restoration however results indicate the influence is not as great as for $\mathrm{A} 1$.

Figure 3 shows color coordinates $L^{*}$ (a), $a^{*}(\mathrm{~b})$, and $b^{*}(\mathrm{c})$ for veneering ceramics shade $\mathrm{A} 1$ and Figure 3 shows color coordinates $L^{*}(\mathrm{a}), a^{*}(\mathrm{~b})$, and $b^{*}(\mathrm{c})$ for veneering ceramics shade A1 and A4 on TZP core KT10 with and without shade base ceramics (KT10 SB and KT10) to investigate the effect of shade base ceramics for light colored TZP core, KT10. Shade base ceramic on light colored TZP core decreases $L^{*}$ and increased $a^{*}$ in veneering ceramics shade $\mathrm{A} 1$, however, this tendency was lost for the darker shade of veneering ceramics shade A4. The $b^{*}$ values for KT10 SB was similar to those for KT 10 regardless of white and black background, except for veneering ceramics shade A4 on white background.

Figure 4 shows TP (a) and OP (b) values of veneering ceramics shade A1 and A4 on all TZP core colors. TP values ranged from 1.3 to 3.1 , indicating that translucency was lost after layering veneering ceramics on TZP core, regardless of the TZP color $(p>0.05)$. OP values for veneering ceramics shade $\mathrm{A} 1$ and $\mathrm{A} 4$ were approximately 4 and 16 with TZP core and approximately 2 and 16 without core indicating that the color of TZP did not have an influence the opalescence of the final restorations. For all TZP colors, there were no significant differences in TP value between veneering ceramics $\mathrm{A} 1$ and A4 $(p<0.05)$ whereas, significant differences were seen in OP value. These results confirm that there is no interaction between TZP color and shade of veneering ceramics. 


\section{DISCUSSION}

In this study, the different colors of TZP core had significant influences on certain color coordinates from $L^{*} a^{*} b^{*}$ of veneering ceramics A1 or A4. The darker ceramic shade (A4) had lesser influence on TZP core than the lighter shade (A1), and it is apparent that shade base porcelain influences the optical properties of light colored TZP. Therefore, the null hypothesis that the color of the TZP core has no effect on the final optical properties the final restoration after veneering ceramics so long as the minimally suggested thickness of $1 \mathrm{~mm}$ is met, can be rejected because certain color coordinates significantly change with different core colors. Nevertheless, it can be suggested that the color of TZP core have no effect on translucency and opalescence of the final restoration.

Above results are similar to a study done by Lee $e t$ al. that demonstrated that all CIE $L^{*} a^{*} b^{*}$ values of A2 and A3 layered specimens were significantly influenced by the combination of core and veneering ceramics ${ }^{30}$. Aboushelib et al. also reported that the application of required veneering ceramic over the natural TZP framework resulted in an accurate reproduction of the required color while for colored TZP, application of liner material or deep chroma dentin was necessary to reproduce the necessary color ${ }^{31)}$. In addition, they concluded that using pre-colored TZP frameworks did not offer any direct advantages over the standard natural TZP which is consistent with our findings.

Shade matching is a complicated process and it is difficult to achieve even with adequate ceramic thickness due to the large variety of translucency among core materials at clinically relevant thicknesses ${ }^{17,32)}$. The perceived color of natural teeth is a result of light reflected from the enamel surface, in addition to the effect of light scattering within enamel and dentin before it is ultimately reflected back ${ }^{33)}$. Thus translucency in the layering material to reflect the core color is essential to reproduce natural tooth like properties, and it is one of the primary factors controlling esthetics and a critical consideration in the selection of materials. TP values of TZP core ranged between 7 and 9 , as did both veneering ceramics A1 and A4, and these values are lower than the TP of human enamel and dentin which are 18.7 and 16.7 respectively ${ }^{22}$. When veneering ceramics were layered above TZP cores, TP for all shades decreased to values from 1 to 3 exhibiting minimal translucency. TZP particles are slightly bigger than wavelength of visible light and also have different refractive indexes than the matrix, giving maximal scattering effect and opacity, which explains the lack of translucency in other words, the masking effect of $\mathrm{TZP}^{13,17)}$. In addition Choi et al. reported that the resulting color of restoration can be modified with the veneering porcelain, which is also in agreement with our conclusion ${ }^{13)}$.

The layering is a primary factor that influences the appearance of layered ceramic restorations. Since there were no significant differences among TP for all specimens, this indicates that translucency of the final restoration is independent of the color of the core and veneering ceramics. This corresponds to numerous studies suggesting that thickness is one of the greatest factors contributing to the translucency and color of $\mathrm{ACR}^{18,21)}$. In addition, final restoration does not depend on the core color, the ceramic shade, or the layer of shade base. The lack of translucency after the application of veneering ceramics can be explained by the masking ability of TZP indicating that abutment tooth and luting material most likely are not factors influencing TP.

The presence of a layer of shade base caused an increase in OP for both veneering ceramics A1 and A4 however results were insignificant. Our results demonstrate that the presence of a core contributes to significant change in opalescence however, since the values between the different TZP core colors were statistically insignificant, the core color has no effect on the opalescence of the final restoration. In addition, OP between A1 and A4 differed significantly, indicating that the color of veneering ceramics dictate the final opalescence.

In this research, core thickness was selected as 0.5 $\mathrm{mm}$ for the reason that most ACR consist of a ceramic core of thickness of $0.3 \mathrm{~mm}$ for anterior teeth and 0.5 $\mathrm{mm}$ for posterior teeth. The recommended reduction for most ceramic crowns is $1.5 \mathrm{~mm}$, approximately $0.5 \mathrm{~mm}$ for the core and $1.0 \mathrm{~mm}$ for the veneering ceramic ${ }^{9,30)}$. Anatomically guided frameworks are clinically preferred due to higher fracture resistance ${ }^{34)}$, however uniform framework thickness was used for simplicity sake in order to produce uniform color.

To determine the overall effect of core colors on the final restoration, color differences $(\Delta \mathrm{E} * \mathrm{ab})$ were

Table $2 \Delta \mathrm{E}^{*} \mathrm{ab}$ of $\mathrm{A} 1$ and $\mathrm{A} 4$ between varying TZP cores on white and black background using KT12 as standard for A1 and KT14 for A4

\begin{tabular}{|c|c|c|c|c|}
\hline \multirow{2}{*}{ Zirconia shade } & \multicolumn{2}{|c|}{ Veneering ceramics A1 } & \multicolumn{2}{|c|}{ Veneering ceramics A4 } \\
\hline & White & Black & White & Black \\
\hline KT10 & 1.9 & 1.8 & 1.7 & 1.1 \\
\hline KT12 & $\mathrm{SV}, 0$ & $\mathrm{SV}, 0$ & 1.1 & 0.8 \\
\hline KT14 & 2.1 & 1.4 & $\mathrm{SV}, 0$ & $\mathrm{SV}, 0$ \\
\hline
\end{tabular}

$\mathrm{SV}, 0$ : Standard value, 0 , for $\Delta \mathrm{E}^{*} \mathrm{ab}$ 
calculated using manufacturer recommendation as standards: TZP core KT12 used for ceramic shade A1 and KT14 used for A4 (Table 2). Instructions specify that KT10 be used for any ceramic shade with a layer of shade base. Johnston and Kao suggested the assessment of appearance match by visual observation and clinical colorimetry and reported that the average color difference between compared teeth rated as a "match" in the oral environment was $3.7^{35)}$. As shown above, the value for perceptible color difference remains controversial, nonetheless based on the acknowledged value, both ceramic shades $\mathrm{A} 1$ and $\mathrm{A} 4$ displayed $\Delta \mathrm{E}^{*} \mathrm{ab}$ values generally within the accepted range regardless of core color. This indicates that the color difference among different core colors are negligible and no remarkable visual differences would be observed by a majority of the population. If we were to indicate the cause of color difference between the core colors, it would be the lack of the shade base layer which affected $L^{*}$ and $a^{*}$ for A 1 and $L^{*}$ and $b^{*}$ for A4. When properly veneered, colored TZP frameworks are said to produce clinically acceptable color match and have the capacity to mask a dark background such as a dark tooth or core buildup material ${ }^{13,31}$. Our results are consistent with studies reporting that the veneering ceramic is what modifies the final color of $\mathrm{ACR}^{9,13)}$. This study demonstrated that when colored TZP $0.5 \mathrm{~mm}$ thick were layered with $1 \mathrm{~mm}$ of veneering ceramics, colored TZP core affects optical properties such as OP however not TP. In addition to colored TZP, high translucency TZP has recently been introduced as a solution to improve the esthetics of TZP core restorations. As a consideration, investigation on translucent TZP core on the optical properties of the final restoration should be considered for further research.

TZP frameworks are becoming a popular type of ACR for the reasons discussed above. The clinical significance of this study is that this information can show clinicians that excessive tooth preparation is not necessary with dark colored abutment tooth because the final restoration color will not be severely affected by backing color. This study can also help dental technicians determine whether the recommended color of TZP core is strictly necessary for the area of restoration since this study has indicated the color difference among different core colors will not be indicated by a majority of the population.

\section{CONCLUSION}

Within the limitations of this study, it can be concluded that for veneering ceramic shades A1 and A4, the color of TZP cores had an influence on color coordinates except for $b^{*}$ for $\mathrm{A} 1$ and $a^{*}$ for A4, however there was no remarkable influence on the translucency and opalescence of the final TZP restoration when layered to thicknesses of $1.0 \pm 0.1 \mathrm{~mm}$ with veneering ceramics.

\section{REFERENCES}

1) Reitemeier B, Hänsel K, Kastner C, Walter MH. Metal-ceramic failure in noble metal crowns: 7-Year results of a prospective clinical trial in private practices. Int J Prosthodont 2006; 19: 397-399.

2) Sailer I, Pjetursson BE, Zwahlen M, Hämmerle CHF. A systematic review of the survival and complication rates of all-ceramic and metal-ceramic reconstructions after an observation period of at least 3 years. Part II: fixed dental prostheses. Clin Oral Implants Res 2007; 18: 86-96.

3) Raptis NV, Michalakis KX, Hirayama H. Optical behavior of current ceramic systems. Int J Periodontics Restorative Dent 2006; 26: 31-41.

4) Scarano A, Di Carlo F, Quaranta M, Piattelli A. Bone response to zirconia ceramic implants: an experimental study in rabbits. J Oral Implantol 2003; 29: 8-12.

5) Chan $\mathrm{C}$, Weber $\mathrm{H}$. Plaque retention on teeth restored with full-ceramic crowns: a comparative study. J Prosthet Dent 1986; 56: 666-671.

6) Egawa M, Miura T, Kato T, Saito A, Yoshinari M. In vitro adherence of periodontopathic bacteria to zirconia and titanium surfaces. Dent Mater J 2013; 32: 101-106.

7) Studart AR, Filser F, Kocher P, Luthy H, Gauckler LJ. Mechanical and fracture behavior of veneer-framework composites for all-ceramic dental bridges. Dent Mater 2007; 23: 115-123.

8) Tinschert J, Natt G, Mautsch W, Augthun M, Spiekermann H. Fracture resistance of lithium disilicate-, alumina-, and zirconia-based three-unit fixed partial dentures: a laboratory study. Int J Prosthodont 2001; 14: 231-238.

9) Heffernan MJ, Aquilino SA, Diaz-Arnold AM, Haselton DR, Stanford CM, Vargas MA. Relative translucency of six all-ceramic systems. Part II: core and veneer materials. J Prosthet Dent 2002; 88: 10-15.

10) Shah K, Holloway JA, Denry IL. Effect of coloring with various metal oxides on the microstructure, color, and flexural strength of 3Y-TZP. J Biomed Mater Res B Appl Biomater 2008; 87: 329-337.

11) Alghazzawi TF, Lemons J, Liu P-R, Essig ME, Janowski GM. Evaluation of the optical properties of CAD-CAM generated yttria-stabilized zirconia and glass-ceramic laminate veneers. J Prosthet Dent 2012; 107: 300-308.

12) Yoshida AKI, Miller L, Da Silva JD, Ishikawa-Nagai S. Spectrophotometric analysis of tooth color reproduction on anterior all-ceramic crowns: Part 2: Color reproduction and its transfer from in vitro to in vivo. J Esthet Restor Dent 2010; 22: 53-63.

13) Choi YJ, Razzoog ME. Masking ability of zirconia with and without veneering porcelain. J Prosthodont 2013; 22: 98-104.

14) Chaiyabutr Y, Kois JC, Lebeau D, Nunokawa G. Effect of abutment tooth color, cement color, and ceramic thickness on the resulting optical color of a CAD/CAM glass-ceramic lithium disilicate-reinforced crown. J Prosthet Dent 2011; 105: 83-90.

15) Alqahtani MQ, Aljurais RM, Alshaafi MM. The effects of different shades of resin luting cement on the color of ceramic veneers. Dent Mater J 2012; 31: 354-361.

16) Vichi A, Ferrari M, Davidson CL. Influence of ceramic and cement thickness on the masking of various types of opaque posts. J Prosthet Dent 2000; 83: 412-417.

17) Heffernan MJ, Aquilino SA, Diaz-Arnold AM, Haselton DR, Stanford CM, Vargas MA. Relative translucency of six allceramic systems. Part I: core materials. J Prosthet Dent 2002; 88: 4-9.

18) Kurklu D, Azer SS, Yilmaz B, Johnston WM. Porcelain thickness and cement shade effects on the colour and translucency of porcelain veneering materials. J Dent 2013; 41: 1043-1050.

19) Wang F, Takahashi H, Iwasaki N. Translucency of dental ceramics with different thicknesses. J Prosthet Dent 2013; 110: 14-20. 
20) Shokry TE, Shen C, Elhosary MM, Elkhodary AM. Effect of core and veneer thicknesses on the color parameters of two all-ceramic systems. J Prosthet Dent 2006; 95: 124-129.

21) Bachhav VC, Aras MA. The effect of ceramic thickness and number of firings on the color of a zirconium oxide based all ceramic system fabricated using CAD/CAM technology. J Adv Prosthodont 2011; 3: 57-62.

22) Yu B, Ahn JS, Lee YK. Measurement of translucency of tooth enamel and dentin. Acta Odontol Scand 2009; 67: 57-64.

23) Brodbelt RH, O'Brien WJ, Fan PL. Translucency of dental porcelains. J Dent Res 1980; 59: 70-75.

24) Cho MS, Yu B, Lee YK. Opalescence of all-ceramic core and veneer materials. Dent Mater 2009; 25: 695-702.

25) Wen N, Yi Y, Zhang W, Deng B, Shao L, Dong L, Tian J. The color of $\mathrm{Fe}_{2} \mathrm{O}_{3}$ and $\mathrm{Bi}_{2} \mathrm{O}_{3}$ pigmented dental zirconia ceramic. Key Eng Mat 2010; 434-435: 582-585.

26) Dozić A, Kleverlaan CJ, Meegdes M, van der Zel J, Feilzer AJ. The influence of porcelain layer thickness on the final shade of ceramic restorations. J Prosthet Dent 2003; 90: 563-570.

27) Son HJ, Kim WC, Jun SH, Kim YS, Ju SW, Ahn JS. Influence of dentin porcelain thickness on layered all-ceramic restoration color. J Dent 2010; 38 Suppl 2: e71-77.

28) Shokry TE, Shen C, Elhosary MM, Elkhodary AM. Effect of core and veneer thicknesses on the color parameters of two all-ceramic systems. J Prosthet Dent 2006; 95: 124-129.

29) Arimoto A, Nakajima M, Hosaka K, Nishimura K, Ikeda M, Foxton RM, Tagami J. Translucency, opalescence and light transmission characteristics of light-cured resin composites. Dent Mater 2010; 26: 1090-1097.

30) Lee YK, Cha HS, Ahn JS. Layered color of all-ceramic core and veneer ceramics. J Prosthet Dent 2007; 97: 279-286.

31) Aboushelib MN, Dozic A, Liem JK. Influence of framework color and layering technique on the final color of zirconia veneered restorations. Quintessence Int 2010; 41: e84-89.

32) Douglas RD, Przybylska M. Predicting porcelain thickness required for dental shade matches. J Prosthet Dent 1999; 82: 143-149.

33) Seghi RR, Johnston WM, O'Brien WJ. Spectrophotometric analysis of color differences between porcelain systems. J Prosthet Dent 1986; 56: 35-40.

34) Ferrari M, Giovannetti A, Carrabba M, Bonadeo G, Rengo C, Monticelli F, Vichi A. Fracture resistance of three porcelainlayered CAD/CAM zirconia frame designs. Dent Mater 2014; 30: e163-168.

35) Johnston WM, Kao EC. Assessment of appearance match by visual observation and clinical colorimetry. J Dent Res 1989; 68: 819-822. 